\title{
8 Weeks of Resistance Training Effect on Myostatin Gene Expression of Myocardium in Healthy Male Wistar Rats
}

\author{
Rashidlamir A.* PhD, Basami M.R. ${ }^{1}$ PhD, Attarzadeh Hosseini S.R. ${ }^{2}$ PhD, \\ Hejazi K. ${ }^{2}$ PhD, Motevalli Anberani S.M. ${ }^{2}$ MSc
}

*Sport Physiology Department, Sport Sciences Faculty, Ferdowsi University of Mashhad, Mashhad, Iran ${ }^{1}$ Clinical Sciences Department, Veterinary Medicine School, Ferdowsi University of Mashhad, Mashhad, Iran ${ }^{2}$ Sport Physiology Department, Sport Sciences Faculty, Ferdowsi University of Mashhad, Mashhad, Iran

\begin{abstract}
Aims: Based on the clinical studies, there are higher myostatin gene expression and serum level in cardiovascular patients than the healthy persons. In addition, based on some studies, regular resistance exercises is in line with a reduction in the myostatin gene expression. The aim of this study was to investigate the effects of 8-week resistance exercises on the myostatin gene expressions of myocardium in the healthy male Wistar rats.

Materials \& Methods: In the experimental study, 13 male adult Wistar rats, aged 15 weeks, were divided into experimental $(n=7)$ and control $(n=6)$ groups. In experimental group, 8-week exercises were done as climbing up a 26-step 1meter ladder, inclined $85^{\circ}$, with a sinker. (There were 3 sessions a week exercises; each session consisted of 3 sets of 5 repetitions.) 24 hours after the last exercise session and after 12-hour fasting, the rats being dissected, muscle tissue samples were prepared to assess mRNA levels. Data was analyzed in SPSS 16 software using independent T test.

Findings: After 8-week resistance exercises, there was no significant difference in the myostatin mRNA expression level in the myocardium between experimental $(1.56 \pm 0.44)$ and control $(1.94 \pm 0.55)$ groups $(\mathrm{p}=0.197)$.

Conclusion: 8-week resistance exercises leads to no significant change in the myostatin gene expression of myocardium in the healthy Wistar male rats.
\end{abstract}

Keywords

Myostatin [http://www.ncbi.nlm.nih.gov/mesh/68055435];

Gene Expression [http://www.ncbi.nlm.nih.gov/mesh/68015870];

Resistance Training [http://www.ncbi.nlm.nih.gov/mesh/68055070];

Myocardium [http://www.ncbi.nlm.nih.gov/mesh/68009206]

\footnotetext{
* Corresponding Author

Tel: +98518833910

Fax: +98518829580

Address: Faculty of Physical Education and Sport Sciences, Paradise Daneshgah, Azadi Square, Ferdowsi University of Mashhad, Mashhad, Iran. Post code: 91779-48979

rashidlamir@um.ac.ir

Received: May 6, $2015 \quad$ Accepted: January 2, 2016 ePublished: March 5, 2016
} 
مقدمه

بيمارىهاى قلبى- عروقى در حال حاضر جزو سه علت اول

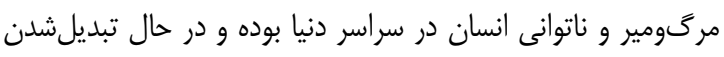

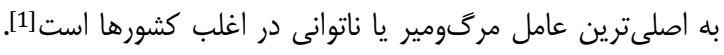

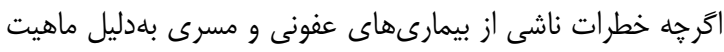

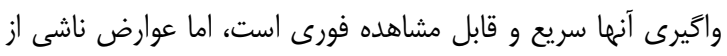

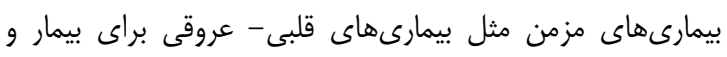

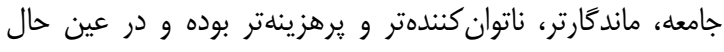

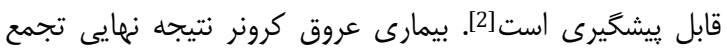
يالاكتهاى آترومايى در داخل ديوارههاى عروق كرونر است كه يه اكسيثن و مواد غذايى را براى ميوكارديوم فراهم مى كنند. اين

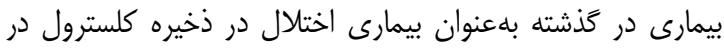

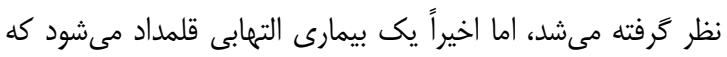
برهم كنش يِيجيدهاى از عوامل خطرساز از جمله سلولهاى دئل ديواره

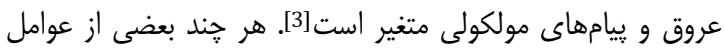

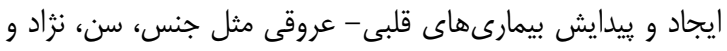

زنتيك غيرقابل مداخله هستند [4].

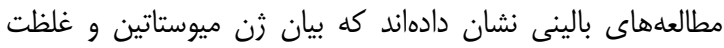
سرمى آن در بيمارى قلبى - عروقى نسبت به افراد سالم بيشتر

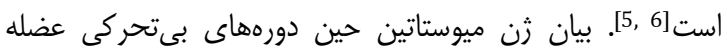

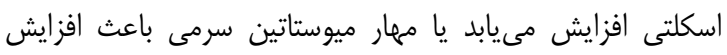

$$
\text { قدرت و توده عضلانى مىشود [7]. }
$$

ميوستاتين يروتئينى است كه بلوسيله سلولهاى عضى عضلات اسكلتى

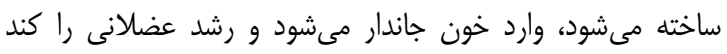

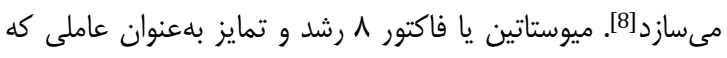
منجر به ماهيجه مضاعف مىشود، معرفى شده است. ثن ميوستاتين

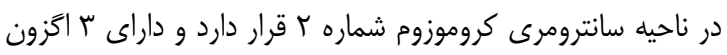
و r اينترون در ناحيه پاييندست زن است. ميوستاتين باعث

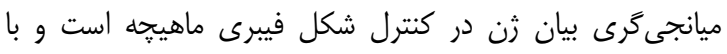

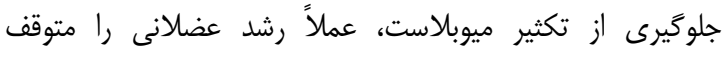

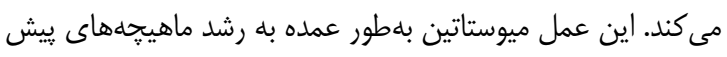

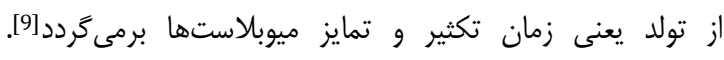

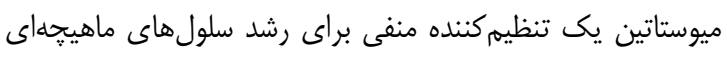

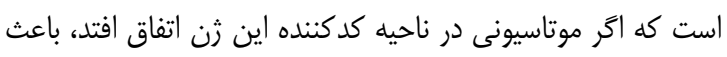

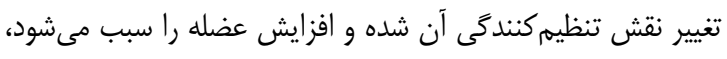
كه اين امر از طريق افزايش سنتز يروتئين صورت مى تقيرد [10].

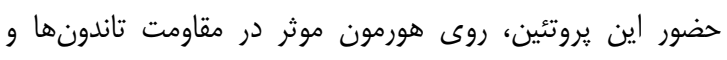

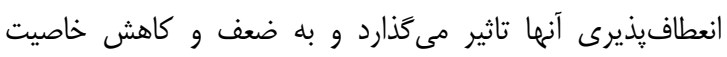

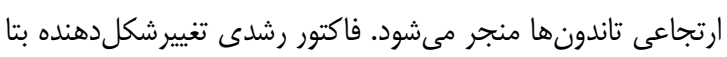

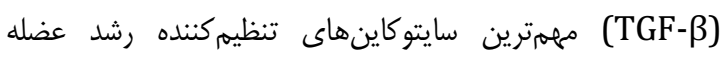
اسكلتى هستند. ميوستاتين بهعنوان عضوى از اين خانواده نقش

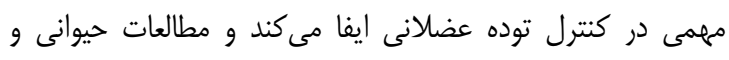

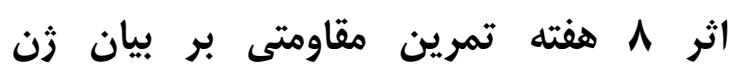
ميوستاتين عضله قلبى در موشهن مارئ نر ويستار سالم ميوسنتاتير PhD كروه فيزيولوزى ورزش، دانشكده علوم ورزشى، دانشخاه فردوسى مشهد، مشهرد، ايران

محمدر إن باسامى PhD

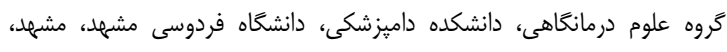
ايران

سيدر ضا عطارزاده حسينى PhD كروه فيزيولوزى ورزش، دانشكده علوم ورزشى، دانشخاه فردوسى مشهل، مشهل، ايران كيوان حجازى كروه فيزيولوزى ورزش، دانشكده علوم ورزشى، دانشگاه فردوسى مشهد، مشهل، ايران

MSc سيدمحمد متولى عنبر انى

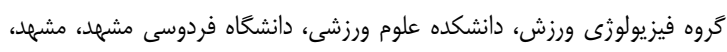
ايران

جكيده اهداف: مطالعات بالينى نشان دادهاند كه بيان ثن ميوستاتين و غلظت سرمى آن در بيماران قلبى - عروقى نسبت به افراد سالم بيشتر است. از باز

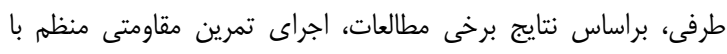

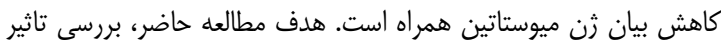

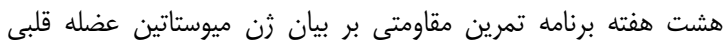

موشهاى نر ويستار سالم بود.

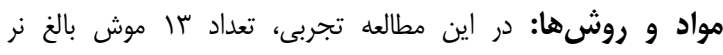

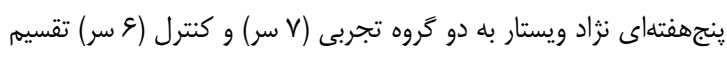

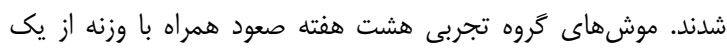

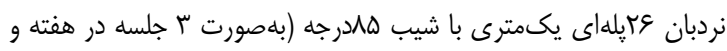

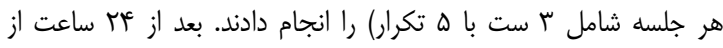

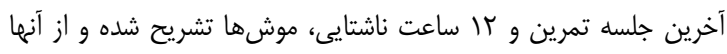

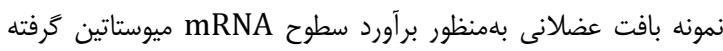

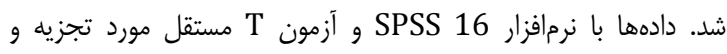

تحليل قرار گرفتند.

يافتهها: بعد از هشت هفته تمرين مقاومتى، تفاوت معنىدارى در سطح

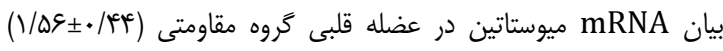

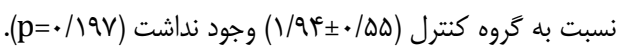

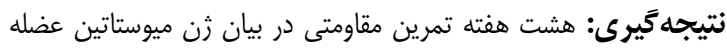
قلبى موشهاى نر ويستار سالم، تغيير معنى دارى ايجاد نمى كند.

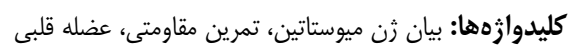

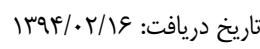

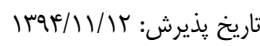
rashidlamir@um.ac.ir :نويسنده مسئول: تاريرش:

دوره rז، شماره ז، بعار هوسا

فصلنامه افق دانش 


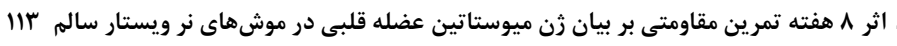

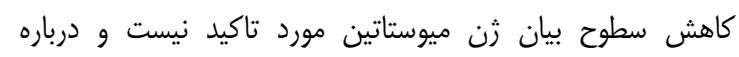

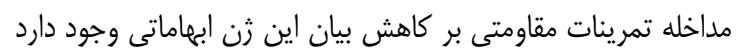

و نيز مطالعات محدودى انجام شده است. با نظر به اهميت تاثير مثبت تمرينات مقاومتى در نوتوانى و افزايش النيات

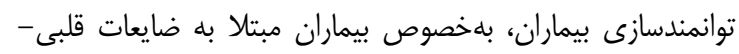

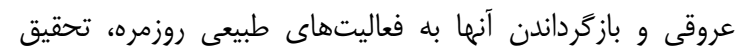

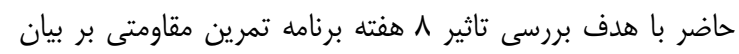

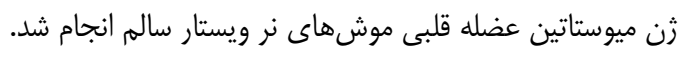

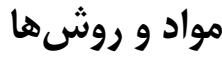

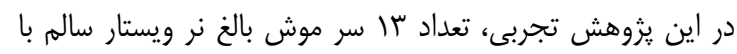

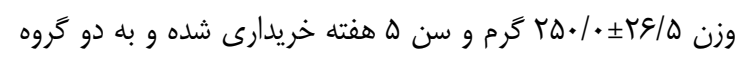

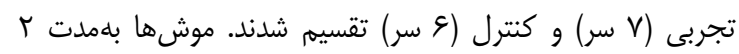

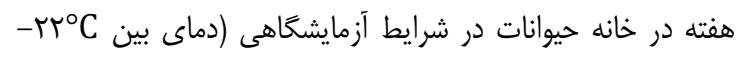

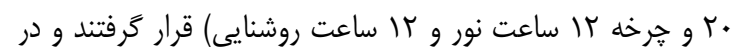

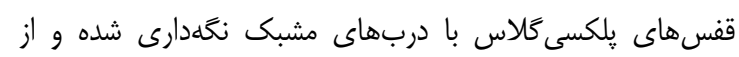

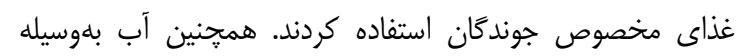

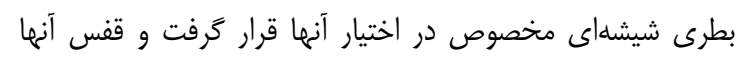

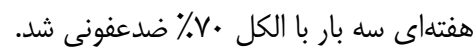

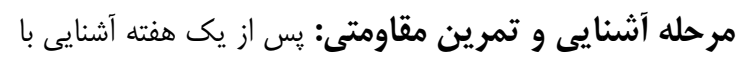

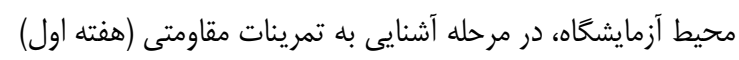

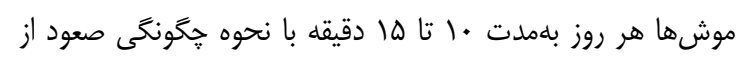

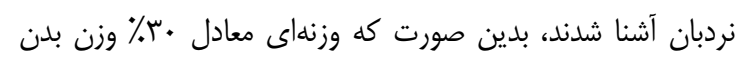

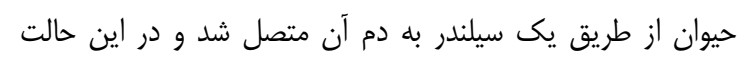

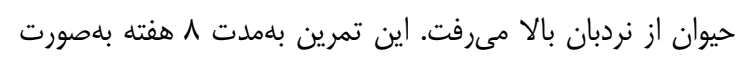

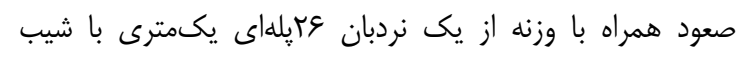

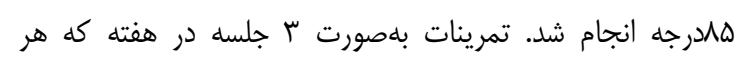

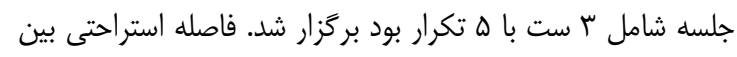

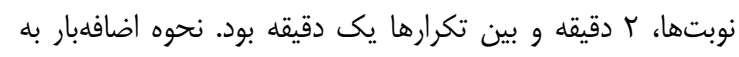

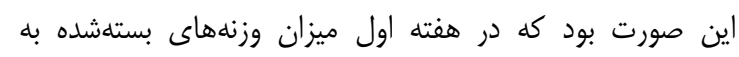

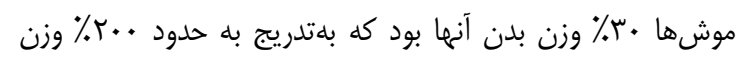

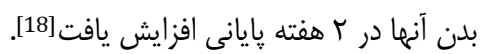

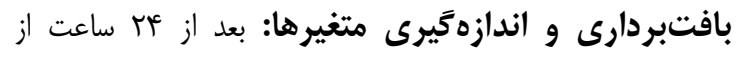

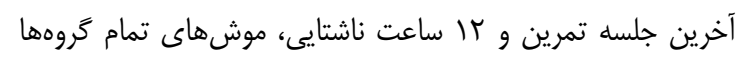

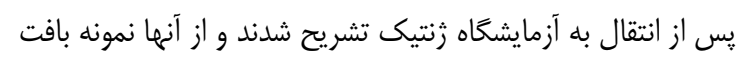

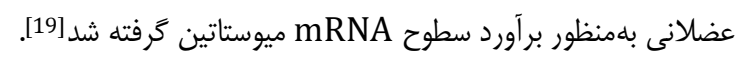

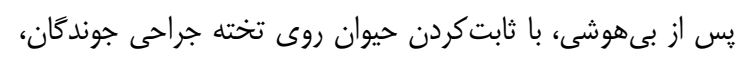

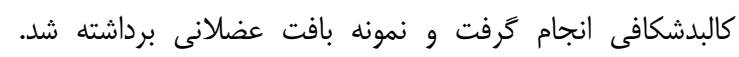

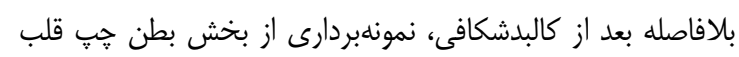

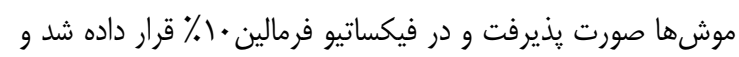

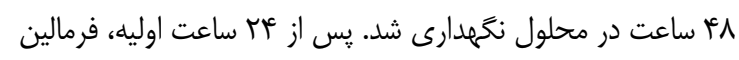

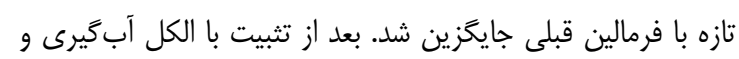

انسانى نشاندهنده نقش تنظيمى منفى ميوستاتين در رشد عضله اسكلتى است[11]].

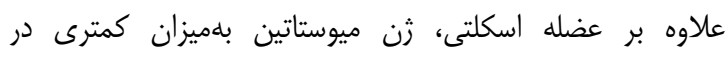

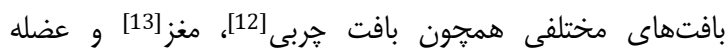

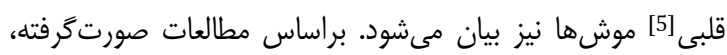

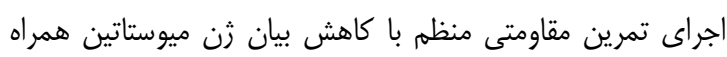

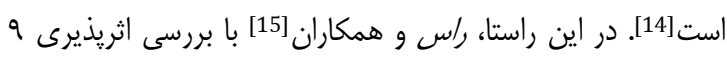

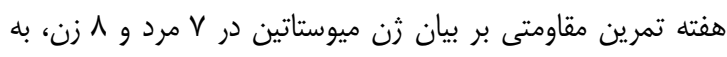

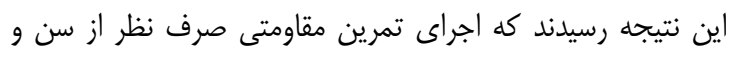

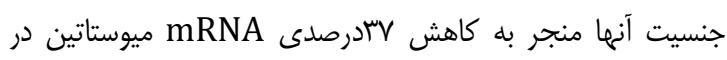

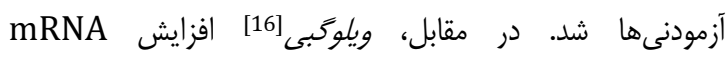

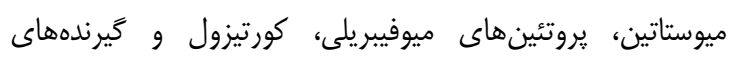

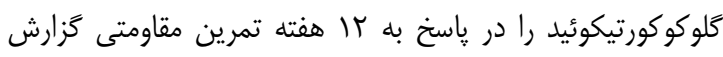

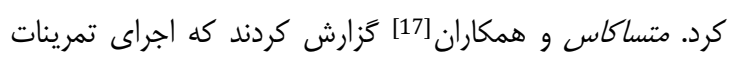

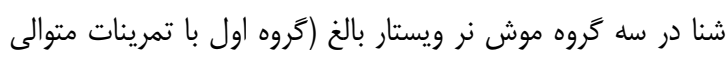

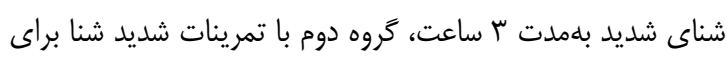

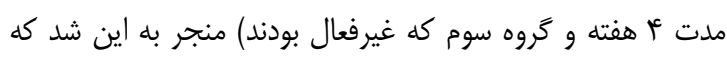

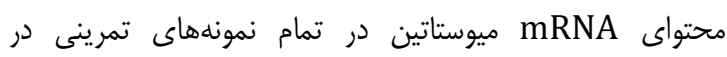

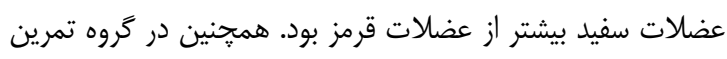

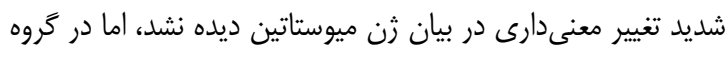

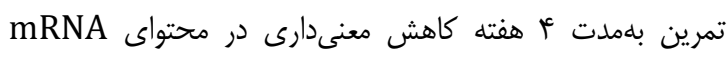

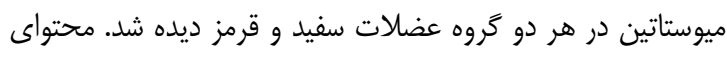

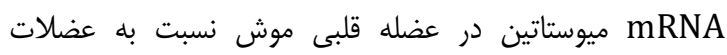

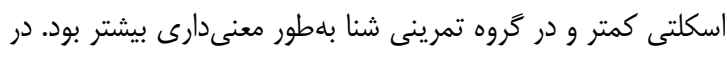

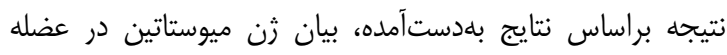

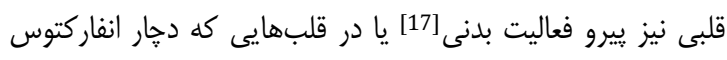

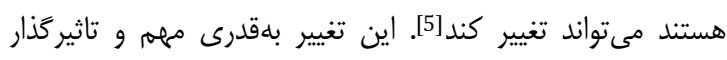

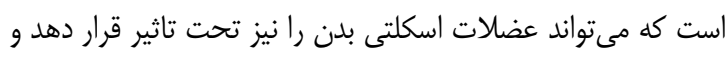
موجب آتروفى آنها شود [6].

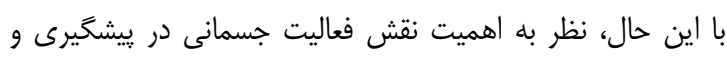

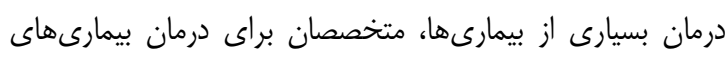

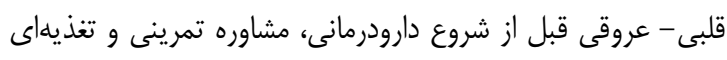

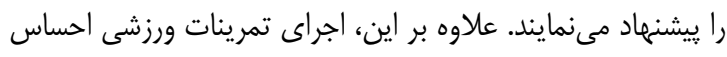

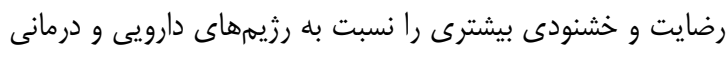

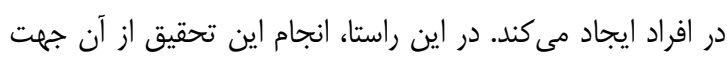

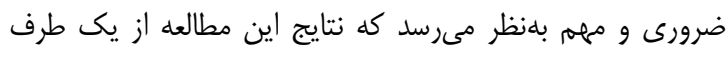

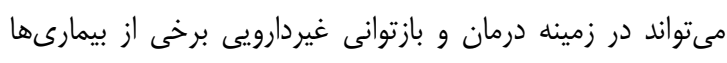

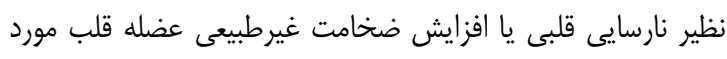

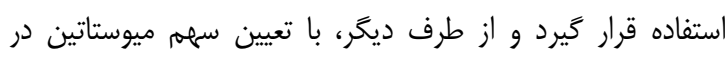

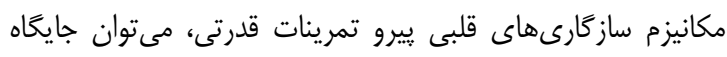

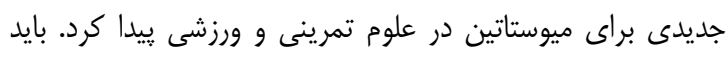

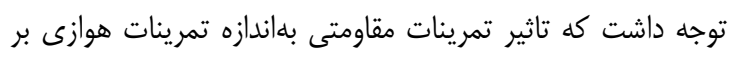




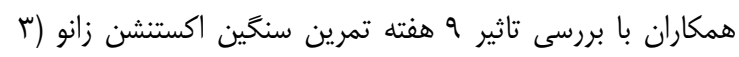

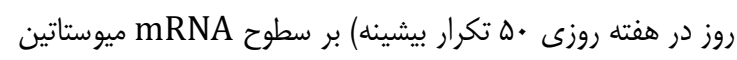

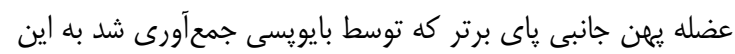

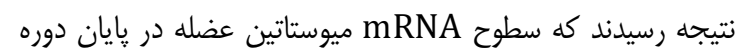

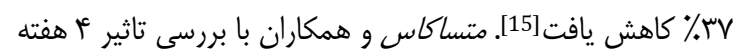

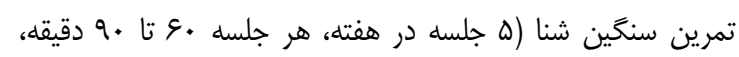

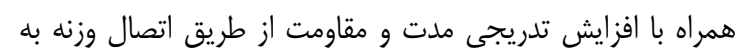

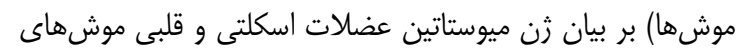

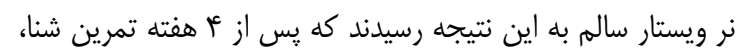

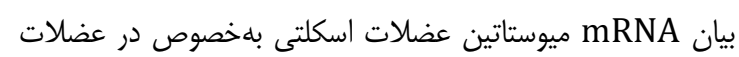

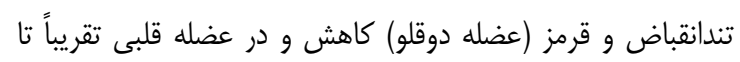

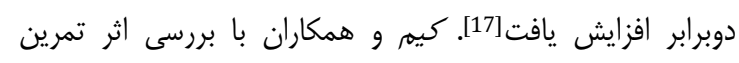

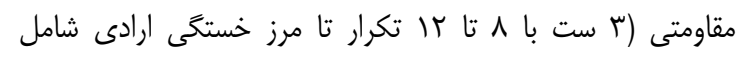

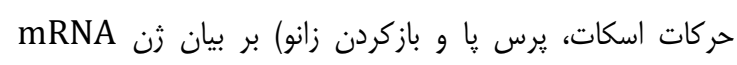

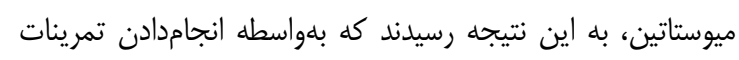

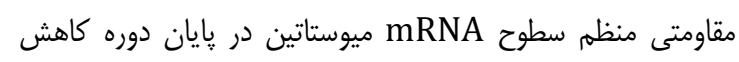

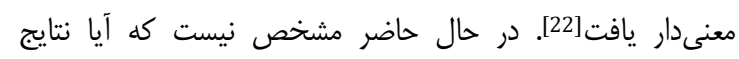

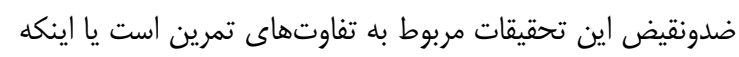

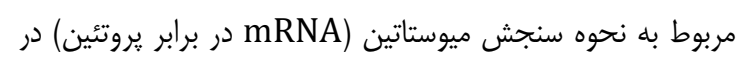

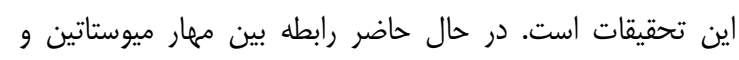

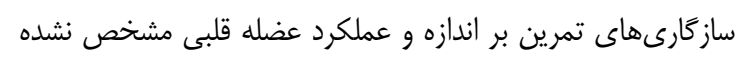

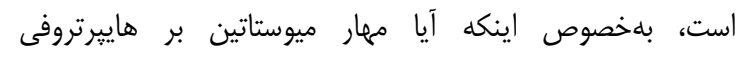

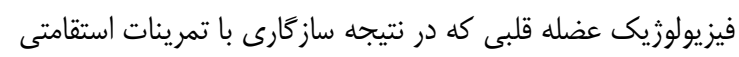

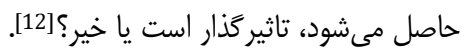

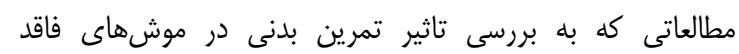

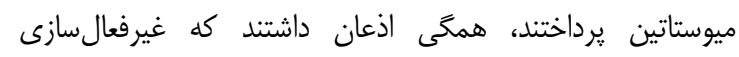

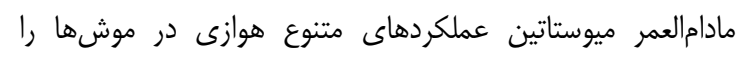

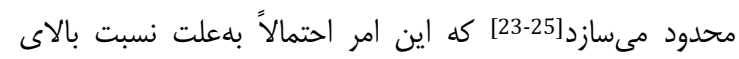

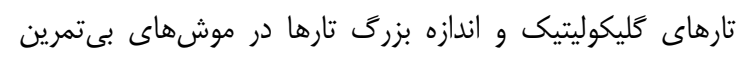

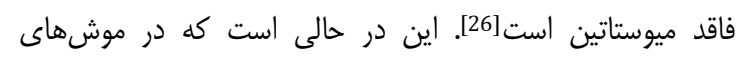

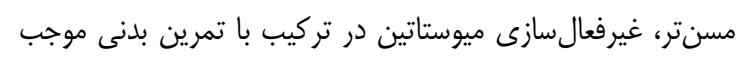

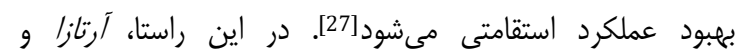

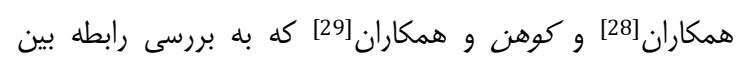

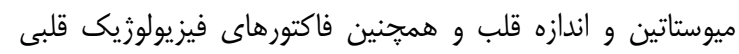

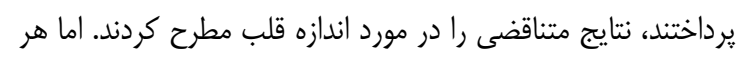

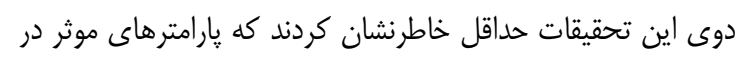

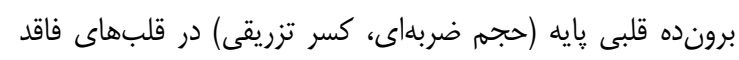

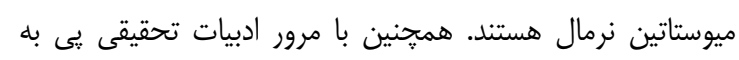

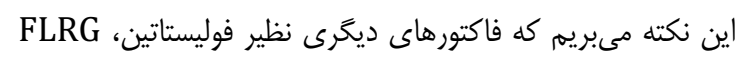

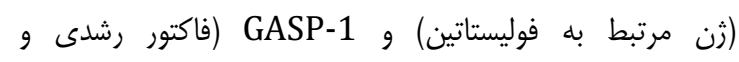

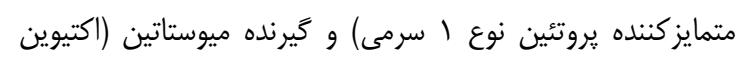
IIb

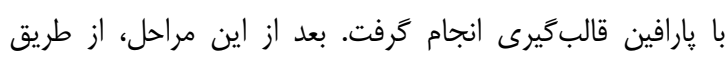

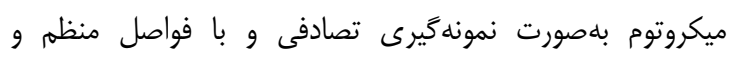

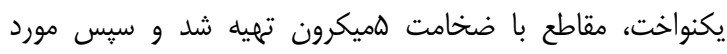

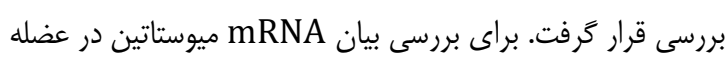

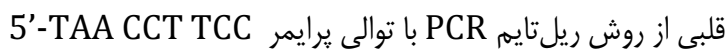
CAG GAC CAG GA-3' براى انجام واكنش ريلتايم PCR از دستخاه Chromo و تركيب

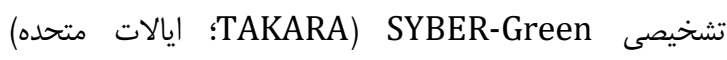
استفاده شد. در اين راستا، مواد مورد نياز به تيوبهاى مخصوص

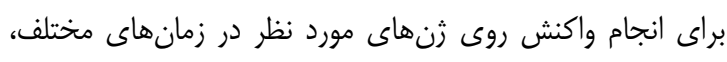

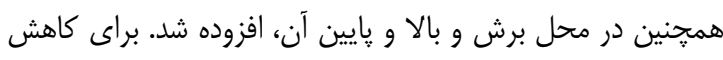

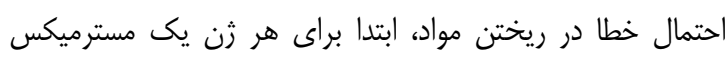

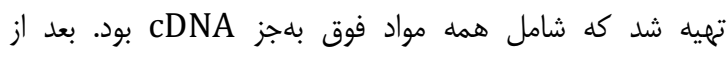

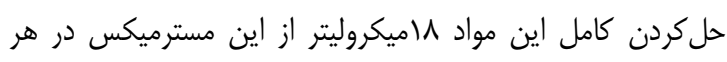

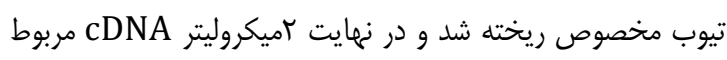

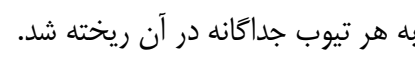
بررسىهاى آمارى: در بايان، دادههاى جمع آورى شده با نرمافزار SPSS 16

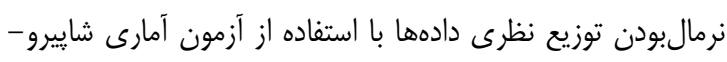

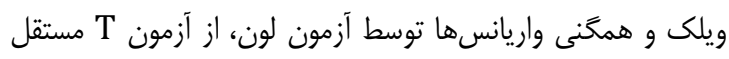
براى بررسى تفاوت ميانخينهاى بين كروهى استفاده شد.

\section{يافتهها}

بعد از هشت هفته تمرين مقاومتى، تفاوت معنى دارى در سطح بيان

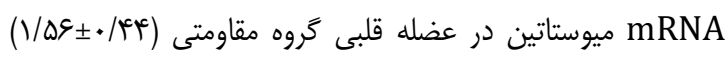

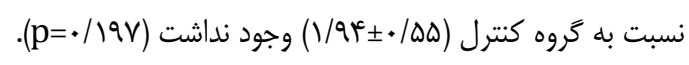

\section{بحث}

هدف از مطالعه حاضر بررسى تاثير 1 هفته تمرين مقاومتى بر بيان

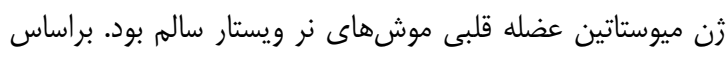

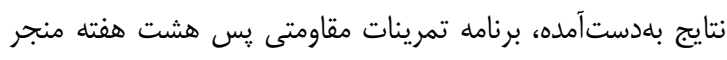

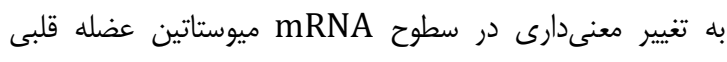

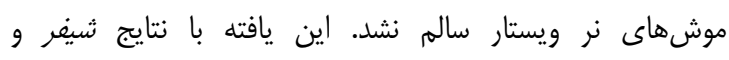

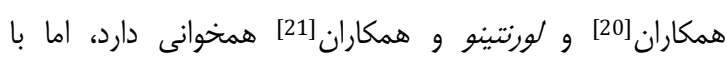

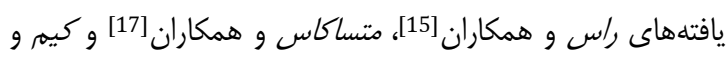

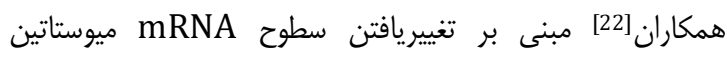

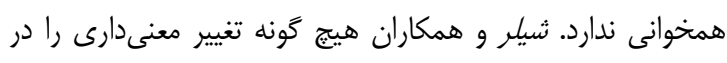

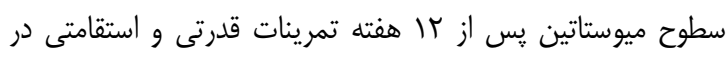

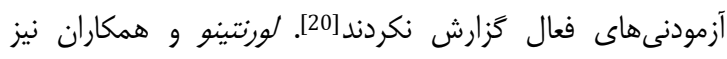

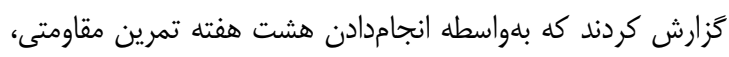
سطوح mRNA اكتيوين IIb عضله بدون تغيير ماند [21]. راس و مقاونى 


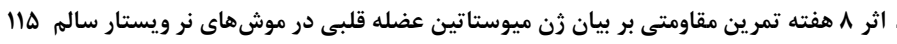

in sedentary middle-aged women. J Shahid Sadoughi Univ Med Sci. 2013;21(4):415-27. [Persian]

5- Sharma M, Kambadur R, Matthews KG, Somers WG, Devlin GP, Conaglen JV, et al. Myostatin, a transforming growth factor-beta superfamily member, is expressed in heart muscle and is upregulated in cardiomyocytes after infarct. J Cell Physiol. 1999;180(1):1-9.

6- Heineke J, Auger-Messier M, Xu J, Sargent M, York A, Welle $S$, et al. Genetic deletion of myostatin from the heart prevents skeletal muscle atrophy in heart failure. Circ. 2010;121(3):419-25.

7- Lee SJ, Lee YS, Zimmers TA, Soleimani A, Matzuk MM, Tsuchida K, et al. Regulation of muscle mass by follistatin and activins. Mol Endocrinol. 2010;24(10):1998-2008.

8- Casas E, Shackelford SD, Keele JW, Stone RT, Kappes SM, Koohmaraie M. Quantitative trait loci affecting growth and carcass composition of cattle segregating alternate from of myostatin. J Anim Sci. 2000;78(3):5609.

9- Walsh FS, Celeste AJ. Myostatin: A modulator of skeletal-muscle stem cells. Biochem Soc Trans. 2005;33(6):1513-7.

10- Kambadur R, Sharma M, Smith TP, Bass JJ. Mutations in myostatin (GDF8) in double-muscled Belgian Blue and Piedmontese cattle. Genome Res. 1997;7(9):910-6.

11- McPherron AC, Lawler AM, Lee SJ. Regulation of skeletal muscle mass in mice by a new TGF-p superfamily member. Nature. 1997;387(6628):83-90.

12- Allen DL, Cleary AS, Speaker KJ, Lindsay SF, Uyenishi J, Reed JM, et al. Myostatin, activin receptor IIb, and follistatin-like-3 gene expression are altered in adipose tissue and skeletal muscle of obese mice. Am J Physiol Endocrinol Metab. 2008;294(5):E918-27.

13- Lein ES, Hawrylycz MJ, Ao N, Ayres M, Bensinger A, Bernard A, et al. Genome-wide atlas of gene expression in the adult mouse brain. Nat. 2007;445(7124):168-76.

14- Saremi A, Gheraati M. The effect of resistance training on serum myostatin level and insulin resistance in obese-overweight men. J Sport Biosci. 2010;2(4):93108. [Persian]

15- Roth SM, Martel GF, Ferrell RE, Metter EJ, Hurley BF, Rogers MA. Myostatin gene expression is reduced in humans with heavy-resistance strength training: a brief communication. Exp Biol Med. 2003;228(6):706-9.

16- Willoughby DS. Effects of heavy resistance training on myostatin mRNA and protein expression. Med Sci Sport Exerc. 2004;36(4):574-82.

17- Matsakas A, Bozzo C, Cacciani N, Caliaro F, Reggiani $\mathrm{C}$, Mascarello $\mathrm{F}$, et al. Effect of swimming on myostatin expression in white and red gastrocnemius muscle and in cardiac muscle of rats. Exp Physiol. 2006;91(6):98394.

18- Lee S, Farrar RP. Resistance training induces musclespecific changes in muscle mass and function in rat. J Exerc Physiol Online. 2003;6(2):80-7.

19- Lenk K, Schur R, Linke A, Erbs S, Matsumoto Y, Adams $\mathrm{V}$, et al. Impact of exercise training on myostatin expression in the myocardium and skeletal muscle in a chronic heart failure model. Euro J Heart Fail. 2009;11(4):342-8.

20- Schiffer T, Geisler S, Sperlich B, Strüder HK. MSTN mRNA after varying exercise modalities in humans. Int J Sports Med. 2011;32(9):683-7.

21- Laurentino GC, Ugrinowitsch C, Roschel H, Aoki MS, Soares AG, Neves M Jr, et al. Strength training with blood How restriction diminishes myostatin gene expression. Med Sci Sport Exerc. 2012;44(3):406-12.

$$
\begin{aligned}
& \text { اعمال ميوستاتين را تحت تاثير خود قرار دهند. در اين زمينه اعمال }
\end{aligned}
$$

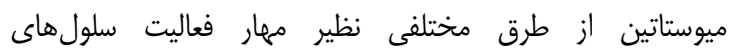

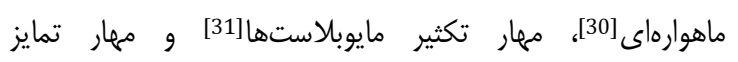

$$
\begin{aligned}
& \text { مايوزنيك[32] انجام مى شودا، }
\end{aligned}
$$

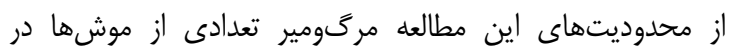

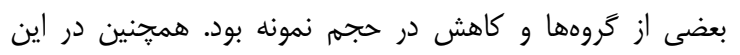

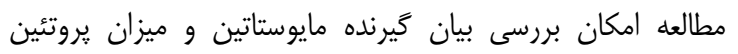

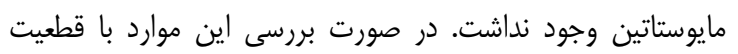

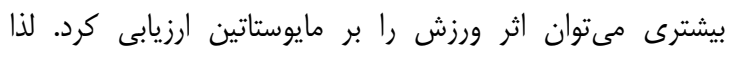

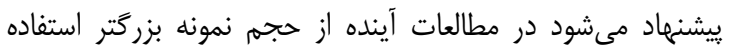

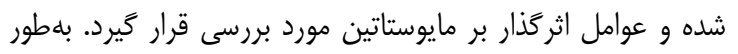

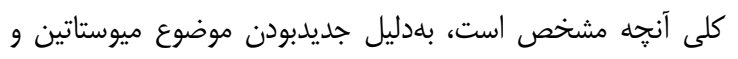

$$
\begin{aligned}
& \text { همجنين حضور ميوستاتين در بافتهاى مختلف بدن، به به تحقيقات }
\end{aligned}
$$

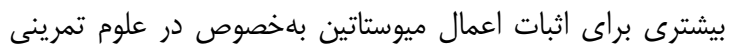

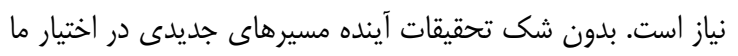

$$
\begin{aligned}
& \text { قرار خواهد داد تا بتوانيم با اطمينان خاطر بيشترى از ميوستاتين } \\
& \text { سخن بخوييهم. } \\
& \text { نتيجه تيرى }
\end{aligned}
$$

^ هفته تمرين مقاومتى در بيان زن ميوستاتين عضله قلبى موش هاى نر ويستار سالم تغييرى ايجاد نمى كند.

$$
\begin{aligned}
& \text { تشكر و قدردانى: بدين وسيله از زحمات بىدريغ تمامى افرادى }
\end{aligned}
$$

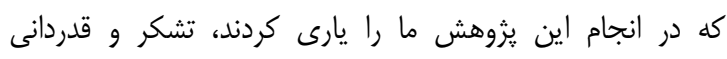

$$
\begin{aligned}
& \text { مى نماييهم. } \\
& \text { تاييديد اخلاقى: موردى توسط نويسندگان گزارش نشده است. } \\
& \text { تعارض منافع: موردى توسط نويسندگان گزارش نشده است. }
\end{aligned}
$$

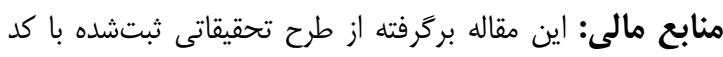

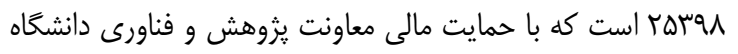

$$
\begin{aligned}
& \text { فردوسى مشهر انجام شده است. } \\
& \text { منابع }
\end{aligned}
$$

1- Sasaki J, Santos M. The role of aerobic exercise on endothelial function and on cardiovascular risk factors. Arq Bras Cardiol. 2006;87(5):e226-31.

2- Tarakji KG, Sabik JF 3rd, Bhudia SK, Batizy LH, Blackstone EH. Temporal onset, risk factors, and outcomes associated with stroke after coronary artery bypass grafting. J Am Med Assoc. 2011;305(4):381-90.

3- Jouyan N, Saffari B, Davoudi-Dehaghani E, Saliani N, Senemar S, Bahari M, et al, Association of usf1s2 variant in the upstream stimulatory factor 1 gene with premature coronary artery disease in southern population of Iran. Tehran Univ Med J. 2015;72(12):83846. [Persian]

4- Bijeh N, Hejazi K. The effect of a six- month aerobic exercise on levels of GH, IGF-1 and GH/IGF-1 ratio serum

\section{-}

smanem 
enhances the effects of exercise on performance and metabolic outcomes in aged mice. J Gerontol A Biol Sci Med Sci. 2009;64(9):940-8.

28- Artaza JN, Reisz-Porszasz S, Dow JS, Kloner RA, Tsao $\mathrm{J}$, Bhasin $\mathrm{S}$, et al. Alterations in myostatin expression are associated with changes in cardiac left ventricular mass but not ejection fraction in the mouse. J Endocrinol. 2007;194(1):63-76.

29- Cohn RD, Liang HY, Shetty R, Abraham T, Wagner KR. Myostatin does not regulate cardiac hypertrophy or fibrosis. Neuromuscul Disord. 2007;17(4):290-6.

30- McCroskery S, Thomas M, Maxwell L, Sharma M, Kambadur R. Myostatin negatively regulates satellite cell activation and self-renewal. J Cell Biol. 2003;162(6):1135-47.

31- Thomas M, Langley B, Berry C, Sharma M, Kirk S, Bass J, et al. Myostatin, a negative regulator of muscle growth, functions by inhibiting myoblast proliferation. J Biol Chem. 2000;275(51):40235-43.

32- Ríos R, Carneiro I, Arce VM, Devesa J. Myostatin is an inhibitor of myogenic differentiation. American Am J Physiol Cell Physiol. 2002;282(5):C993-9.
22- Kim JS, Cross JM, Bamman MM. Impact of resistance loading on myostatin expression and cell cycle regulation in young and older men and women. Am J Physiol Endocrinol Metab. 2005;288(6):E1110-9.

23- Matsakas A, Mouisel E, Amthor H, Patel K. Myostatin knockout mice increase oxidative muscle phenotype as an adaptive response to exercise. J Muscle Res Cell Motil. 2010;31(2):111-25.

24- Personius KE, Jayaram A, Krull D, Brown R, Xu T, Han $\mathrm{B}$, et al. Grip force, EDL contractile properties, and voluntary wheel running after postdevelopmental myostatin depletion in mice. J Appl Physiol. 2010;109(3):886-94.

25- Louis E, Raue U, Yang Y, Jemiolo B, Trappe S. Time course of proteolytic, cytokine, and myostatin gene expression after acute exercise in human skeletal muscle. J Appl Physiol. 2007;103(5):1744-51.

26- Schiffer T, Geisler S, Sperlich B, Strüder HK. MSTN mRNA after varying exercise modalities in humans. Int J Sports Med. 2011;32(9):683-7.

27- LeBrasseur NK, Schelhorn TM, Bernardo BL, Cosgrove PG, Loria PM, Brown TA. Myostatin inhibition 